\title{
Differential response to carotid sinus pressure during sinus rhythm and atrial fibrillation
}

\author{
K J HELLESTRAND, A W NATHAN, A J CAMM \\ From Department of Cardiology, St Bartholomew's Hospital, London
}

SUMMARY In a patient who presented with syncope and palpitation left carotid sinus massage resulted in prolonged ventricular asystole during atrial fibrillation. In the same patient left carotid sinus stimulation during sinus rhythm produced no change in sinus rate and only slight PR interval prolongation. This very different response may be the result of factors which are relevant only during atrial fibrillation such as an increase in the atrial depolarisation frequency and a prolongation of the duration of the atrioventricular nodal concealment zone secondary to increased vagal activity. An increase in atrioventricular nodal refractoriness could not explain this differential response.

The cardio-inhibitory form of the hypersensitive carotid sinus reflex is a relatively common and important cause of presyncope in elderly men..$^{1-3}$ Unilateral carotid sinus massage has a variable effect on both sinus node automaticity and atrioventricular nodal conductivity. ${ }^{4}$ Right carotid sinus stimulation, however, appears preferentially to produce sinus node slowing whereas left carotid sinus pressure is more likely to result in atrioventricular nodal conduction delay or block. ${ }^{5}$

We present, in this report, a patient with a history of syncope and paroxysmal atrial fibrillation who during normal sinus rhythm showed little response to right or left carotid sinus massage. Left carotid sinus pressure, however, during atrial fibrillation produced profound bradycardia and presyncope.

\section{Case report}

In April 1980, a 70-year-old man was referred for investigation of palpitation accompanied by presyncope and syncope. These symptoms had been occurring intermittently over the preceding 10 weeks. The patient had observed that during episodes of palpitations, presyncope could be precipitated by head turning. Twenty-four hour ambulatory electrocardiographic monitoring before admission showed sinus rhythm with intermittent sinus bradycardia, occasional Wenckebach atrioventricular block, and one episode of atrial flutter lasting four minutes.

In May 1980, the patient again presented complaining of a presyncopal episode and palpitation. At this time a 12 lead electrocardiogram showed atrial fibrilla- tion with a variable ventricular response ( 75 to 145 beats per min). Physical examination disclosed normal cardiovascular findings apart from intermittent atrial fibrillation. No carotid bruits were heard. Chest radiography showed a normal cardiothoracic ratio, cardiac silhouette, and pulmonary vascularity. Routine haematology and biochemistry were also within normal limits.

While in atrial fibrillation and with continuous electrocardiographic monitoring carotid sinus stimulation was performed (Fig. 1). During right carotid sinus massage for 10 seconds a transient slowing of the ventricular rate occurred, the longest $R R$ interval being $1.2 \mathrm{~s}$. Left carotid sinus stimulation for $10 \mathrm{~s}$ resulted in a period of $5 \mathrm{~s}$ of ventricular asystole followed by two ventricular complexes and then a further $3 \mathrm{~s}$ of asystole. This response was accompanied by dizziness identical to the patient's spontaneous symptoms.

Four hours after admission spontaneous reversion to sinus rhythm occurred. The 12 lead electrocardiogram showed a sinus rate of 68 beats $/ \mathrm{min}$. The $P$ wave showed left atrial abnormality and the PR interval was slightly prolonged at $0.22 \mathrm{~s}$. The $Q R S$ complex and QT interval were normal. Carotid sinus massage was again performed with continuous electrocardiographic monitoring. There was no alteration in heart rate or rhythm. Left carotid sinus massage resulted in transient $P R$ interval prolongation to $0.26 \mathrm{~s}$ (Fig. 2).

Before insertion of a permanent endocardial pacing system simple electrophysiological investigations were undertaken using a single bipolar pacing catheter positioned in the high right atrium. Continuous stan- 

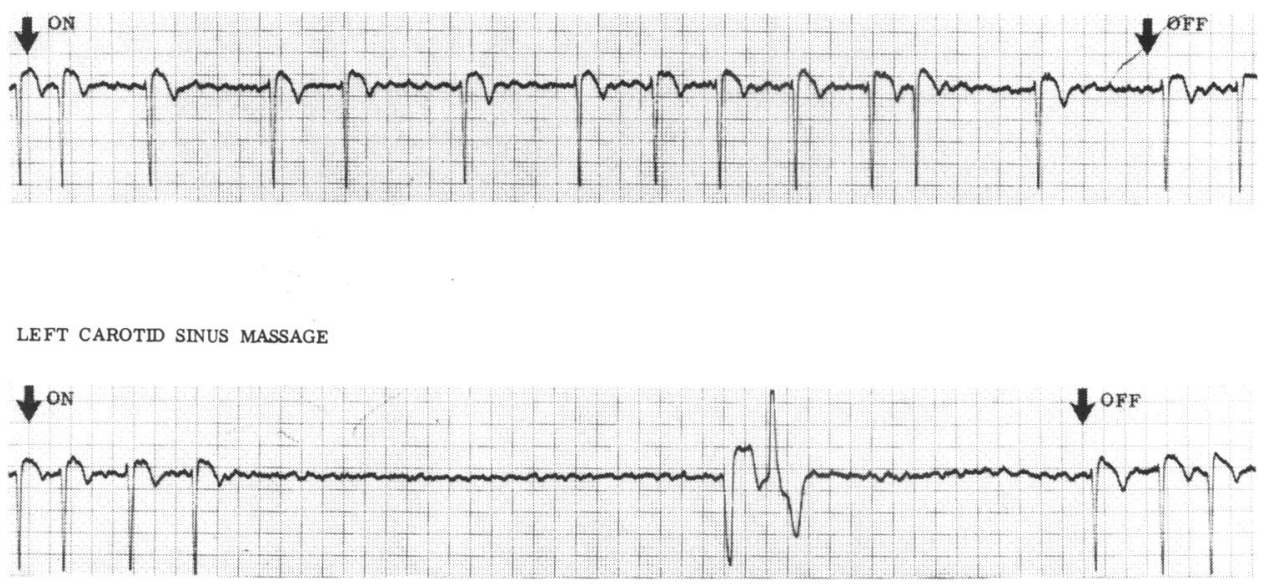

Fig. 1 Differential response to right and left carotid sinus massage during atrial fibrillation.

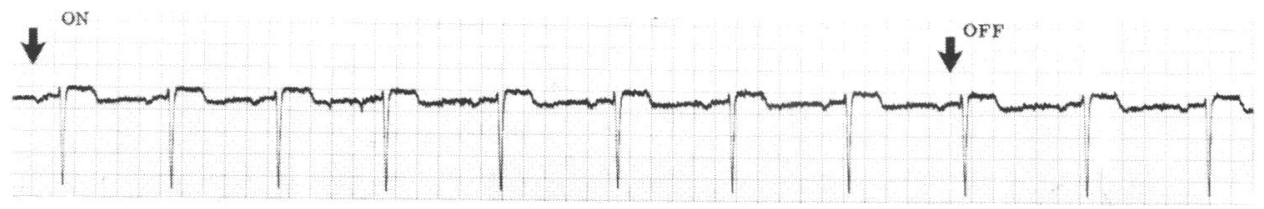

Fig. 2 Effect of left carotid sinus massage after reversion to sinus rhythm.

dard lead II electrocardiographic recordings were made at a paper speed of $50 \mathrm{~mm} / \mathrm{s}$ before and after the administration of $3 \mathrm{mg}$ atropine sulphate intravenously.

The resting PR interval was prolonged at $0.24 \mathrm{~s}$. Abnormal resting values for both the raw and corrected sinus node recovery times were found $(1560 \mathrm{~ms}$ and $620 \mathrm{~ms}$, respectively). The atrioventricular Wenckebach cycle was also prolonged at $500 \mathrm{~ms}$. All electrophysiological abnormalities were corrected after atropine. No direct measurements of $\mathrm{AH}$ or HV intervals were made and it was not possible to initiate atrial arrhythmias during the study. During sinus rhythm, and before giving atropine, however, a variety of vagotonic manoeuvres was performed (carotid sinus stimulation, eyeball pressure, Valsalva manoeuvre). No change in sinus node automaticity occurred in response to vagal stimulation. There was $P R$ interval prolongation of up to $0.26 \mathrm{~s}$ during left carotid sinus massage, which did not occur after atropine.

During the six months after implantation of a ventricular demand pacemaker the patient has remained completely asymptomatic.

\section{Discussion}

The dramatic response to carotid sinus massage observed in our patient during atrial fibrillation which could not be reproduced during sinus rhythm may be explained by several factors which influence atrioventricular conduction during atrial fibrillation but not during sinus rhythm.

Vagal stimulation reduces atrial refractoriness and leads to an increase in atrial fibrillation frequency..$^{6-8}$ Both Moe and Abildskov ${ }^{6}$ and Langendorf et al. ${ }^{8}$ showed an inverse relation between the rate of atrial depolarisation at rapid frequencies and the ensuing ventricular response as a result of incomplete penetration of, or concealed conduction within, the atrioventricular node. The duration of the concealment zone within the atrioventricular node has been shown to be prolonged by increased vagal activity, further reducing the ventricular response. ${ }^{6}$

Vagal stimulation also increases atrioventricular nodal refractoriness and slows atrioventricular nodal conduction. ${ }^{9}$ Since no atrioventricular block occurred during sinus rhythm in response to carotid sinus massage, an increase in atrioventricular nodal refractori- 
ness sufficient to account for the degree of asystole seen in this patient in response to vagal stimulation during atrial fibrillation is very unlikely. Therefore, the increase in atrial input frequency and prolongation of the duration of the atrioventricular nodal concealment zone must account for most of this response.

Treatment of this cardio-inhibitory form of carotid sinus hypersensitivity by ventricular demand pacing was chosen in preference to carotid sinus denervation or anticholinergic drug treatment. Both surgical denervation and radiation treatment of the carotid sinus are unreliable, ${ }^{1011}$ and anticholinergic treatment, in the large doses required to abolish symptoms of carotid sinus hypersensitivity, is poorly tolerated. ${ }^{12}$

\section{References}

1 Hartzler GO, Maloney JD. Cardio-inhibitory carotid sinus hypersensitivity. Arch Intern Med 1977; 137: 72731.

2 Smiddy J, Lewis HD Jr, Dunn M. The effect of carotid massage in older men. F Gerontol 1972; 27: 209-11.

3 Walter PF, Crawley IS, Dorney ER. Carotid sinus hypersensitivity and syncope. Am F Cardiol 1978; 42: 396-403.

4 Heidorn GH, McNamara AP. Effect of carotid sinus stimulation on the electrocardiograms of clinically normal individuals. Circulation 1956; 14: 1104-13.
5 Sigler LH. The cardio-inhibitory carotid sinus reflex; its importance as a vagocardiosensitivity test. Am $\mathcal{f}$ Cardiol 1963; 12: 175-83.

6 Moe GK, Abildskov JA. Observations of the ventricular dysrhythmia associated with atrial fibrillation in the dog heart. Circ Res 1964; 14: 447-60.

7 Méndez C, Méndez R. The action of cardiac glycosides on the excitability and conduction velocity of the mammalian atrium. F Pharmacol Exp Ther 1957; 121: 402-13.

8 Langendorf R, Pick A, Katz LN. Ventricular response in atrial fibrillation. Circulation 1965; 32: 69-75.

9 Narula OS. In: Narula OS, ed. Electrocardiography and clinical electrophysiology. Philadelphia: FA Davis, 1977: 29.

10 Thomas JE. Diseases of the carotid sinus-syncope. In: Vinken PJ, Bruyn GW, eds. Handbook of clinical neurology. vol II. Amsterdam: North-Holland, 1972: 532-51.

11 Greeley HP, Smedal MI, Most W. The treatment of the carotid sinus syndrome by irradiation. $N$ Engl $f$ Med 1955; 252: 91-4.

12 Voss DM, Magnin GE. Demand pacing and carotid sinus syncope. Am Heart $\mathcal{f}$ 1970; 79: 544-7.

Requests for reprints to Dr K J Hellestrand, Department of Cardiology, St Bartholomew's Hospital, West Smithfield, London EC1A 7BE. 